\title{
Decapod Crustaceans of the Headwater Streams of Pohnpei, Eastern Caroline Islands, Federated States of Micronesia ${ }^{1}$
}

\author{
Donald W. Buden, ${ }^{2,3}$ D. Brian Lynch, ${ }^{2}$ fobn W. Short, ${ }^{4}$ and Trina Leberer ${ }^{5}$
}

\begin{abstract}
Two species of Macrobracbium (Palaemonidae) and three atyid shrimp (Atyidae) species were identified among 986 decapod crustaceans collected in headwater streams on Pohnpei, Micronesia, during 1999 and among incidental collections in 2000. None is endemic to the island; all are indigenous or at least not of recent human introduction, and all occur widely in the Indo-West Pacific region and have a diadromous life history pattern. Both Macrobrachium lar (Fabricius, 1798) and M. latimanus (Von Martens, 1868) are common in Pohnpei rivers, but $M$. latimanus outnumbers $M$. lar especially in the uppermost reaches. Atyoida pilipes (Newport, 1847) accounted for $72 \%$ of the atyid sample, and it was the only decapod recorded at elevations as high as $604 \mathrm{~m}$; Caridina weberi (De Man, 1892) composed $21 \%$ of the sample and C. typus (H. Milne Edwards, 1837) $6.4 \%$. Ovigerous females were collected throughout the year for three of the five species; the absence of ovigerous Macrobracbium lar and Caridina typus during August-November was possibly due to small sample sizes. Freshwater shrimps do not currently form an important part of the diet of Pohnpei islanders, but historical accounts suggest that shrimps were utilized more in the past when imported foods and advanced technology for harvesting marine resources were not readily available.
\end{abstract}

INFORMATION ON THE distribution and abundance of the freshwater biota of Micronesian islands is scanty and widely scattered in the literature. Maciolek and Ford (1987) furnished the first comprehensive inventory of stream macrofauna on Pohnpei. They reported on 44 species, including 10 decapod crustaceans (seven atyids, two palaemonids, and one grapsid crab); their samples were

\footnotetext{
${ }^{1}$ Manuscript accepted 17 November 2000.

${ }^{2}$ Division of Natural Science and Mathematics, College of Micronesia, P.O. Box 159, Kolonia, Pohnpei FM 96941 (E-mail: don_buden@comfsm.fm and brianl@comfsm.fm).

${ }^{3}$ Author for contact: (address above, tel.: $691320-$ 2480; fax: 691 320-2479).

${ }^{4}$ Queensland Centre for Biodiversity, Queensland Museum, P.O. Box 3300, South Brisbane, Qld 4101, Australia (E-mail: John.Short@qm.qld.gov.au).

${ }^{5}$ Department of Agriculture, Division of Aquatic and Wildlife Resources, 192 Dairy Road, Mangilao, Guam 96923 (E-mail: cleber@mail.gov.gu).
}

Pacific Science (2001), vol. 55, no. 3:257-265

(C) 2001 by University of Hawai'i Press

All rights reserved largely from the Nanpil-Kiepw River, and at elevations below about $200 \mathrm{~m}$. No other crustaceans were added to this list during subsequent surveys of the Nanpil and Lehn Mesi Rivers (also at sites below about $200 \mathrm{~m}$ ) in 1996 (Nelson et al. 1996); there have been no other surveys. This study is the first report on the distribution of freshwater decapods in headwaters (mainly above $200 \mathrm{~m}$ ) on Pohnpei, and it is based largely on surveys of six rivers during February-November 1999, with ancillary material from March and April 2000. New information is presented on the distribution, relative abundance, morphology, and reproductive condition among two species of Macrobracbium (Palaemonidae), $M$. lar (Fabricius, 1798), and $M$. latimanus (Von Martens, 1868), and three atyid shrimps (Atyidae), including Atyoida pilipes (Newport, 1847), Caridina typus (H. Milne Edwards, 1837), and C. weberi (De Man, 1892).

\section{Study Area}

Pohnpei is a moderately sized $\left(355 \mathrm{~km}^{2}\right.$ [MacLean et al. 1986]), ruggedly mountain- 
ous, tropical Pacific island located $766 \mathrm{~km}$ north of the equator in the eastern Caroline Islands, Federated States of Micronesia (Figure 1). Maximum elevations in the central highlands are just under $800 \mathrm{~m}$ (U.S. Army Corps of Engineers 1986). Densely forested steep ridges and deep valleys give rise to several major watersheds and radiate outward and downward to the coastal lowlands and surrounding mangroves. A discontinuous barrier reef encloses a lagoon up to about $6 \mathrm{~km}$ wide. The average annual air temperature is $27^{\circ} \mathrm{C}$, and the average monthly temperature does not vary from the annual average by more than $1^{\circ}$ (Laird 1982). Mean annual rainfall in Kolonia, the main settlement (on the northern coast), is approximately $485 \mathrm{~cm}$, with estimates for the central highlands ranging to $1015 \mathrm{~cm}$ (Merlin et al. 1992).

The vegetation is largely rain forest dominated by dohng (Campnosperma brevipetiolata) and sadak (Elaeocarpus carolinensis) with patches or stands of the endemic kotop palm (Clinostigma ponapensis). Tree ferns (Cyathea spp.) are common in the understory, and epiphytic mosses and ferns festoon tree trunks, limbs, and branches. Trustrum (1996) reported a decline in native upland forest from about $42 \%$ of vegetation cover in 1975 to about $15 \%$ in 1995 , attributing it largely to clear-cutting of numerous, small plots for cultivating sakau (kava), Piper methysticum. The crushed roots of this plant yield a beverage consumed for its psychoactive properties, and which has long been a part of Pohnpeian tradition and culture. In recent years, however, widespread recreational use has increased the demand, and sakau is the island's most valuable (profitable) cash crop.

The 1994 national census recorded 31,540 people living on Pohnpei, with 6660 of them residing in Kolonia; the others are distributed among smaller settlements mainly along the 87-km-long circumferential road (Office of Planning and Statistics 1996). No roads traverse the island, and the central highlands remain uninhabited. Subsistence farming is widespread near the settlements, and fishing, tourism, and government work contribute to the local economy.

The streams we surveyed averaged about
2-4 $\mathrm{m}$ wide and $0.5-1.0 \mathrm{~m}$ deep, with some pools below waterfalls reaching depths of $3 \mathrm{~m}$. The streambeds consisted largely of boulders and cobbles with some exposed bedrock and small deposits of gravel. Water temperatures ranged from 23 to $27^{\circ} \mathrm{C}$, and elevations at the 33 stations were $146-550 \mathrm{~m}$.

\section{MATERIALS AND METHODS}

Specimens were collected using hand-held dip nets at 33 stations on six rivers (Figure 1) during February-November 1999. All collections were made by D.W.B. and D.B.L., with one or two assistants on several occasions. Most of the stations were visited only once, and none more than three times. We collected specimens opportunistically, but proportionately less effort was spent in pursuit of the largest individuals of Macrobrachium spp., which were more elusive and difficult to capture. We also curtailed collecting species that were abundant at a locality to focus on those less numerous.

Twenty-six stations (79\%) were above $200 \mathrm{~m}$ and accounted for $91 \%(50 \mathrm{hr}$ ) of the search effort, loosely defined to include streamside processing of specimens (including fishes), note taking, and time spent walking along the stream bank at each site, in addition to actual collection time. Inasmuch as search effort included several disparate components, we did not calculate a capture rate index for the shrimp. Stations averaged about 25-50 $\mathrm{m}$ long; some were confined to single pools and others covered as much as $100-150 \mathrm{~m}$ of the streambed. Areas above and below major waterfalls (more than about $8 \mathrm{~m}$ high) were treated as separate stations. Fifty-nine additional specimens collected in the Nanpil, Senipehn, and Neh Rivers in March and April 2000 are mentioned in comparisons but were not pooled with the 1999 samples. All specimens were preserved in $10 \%$ formalin, washed, transferred to $35 \%$ isopropanol, and distributed between the College of Micronesia, the University of Guam, and the Queensland Museum (Australia).

All measurements are in millimeters. For Macrobracbium spp., total length was measured as the distance from the tip of the ros- 


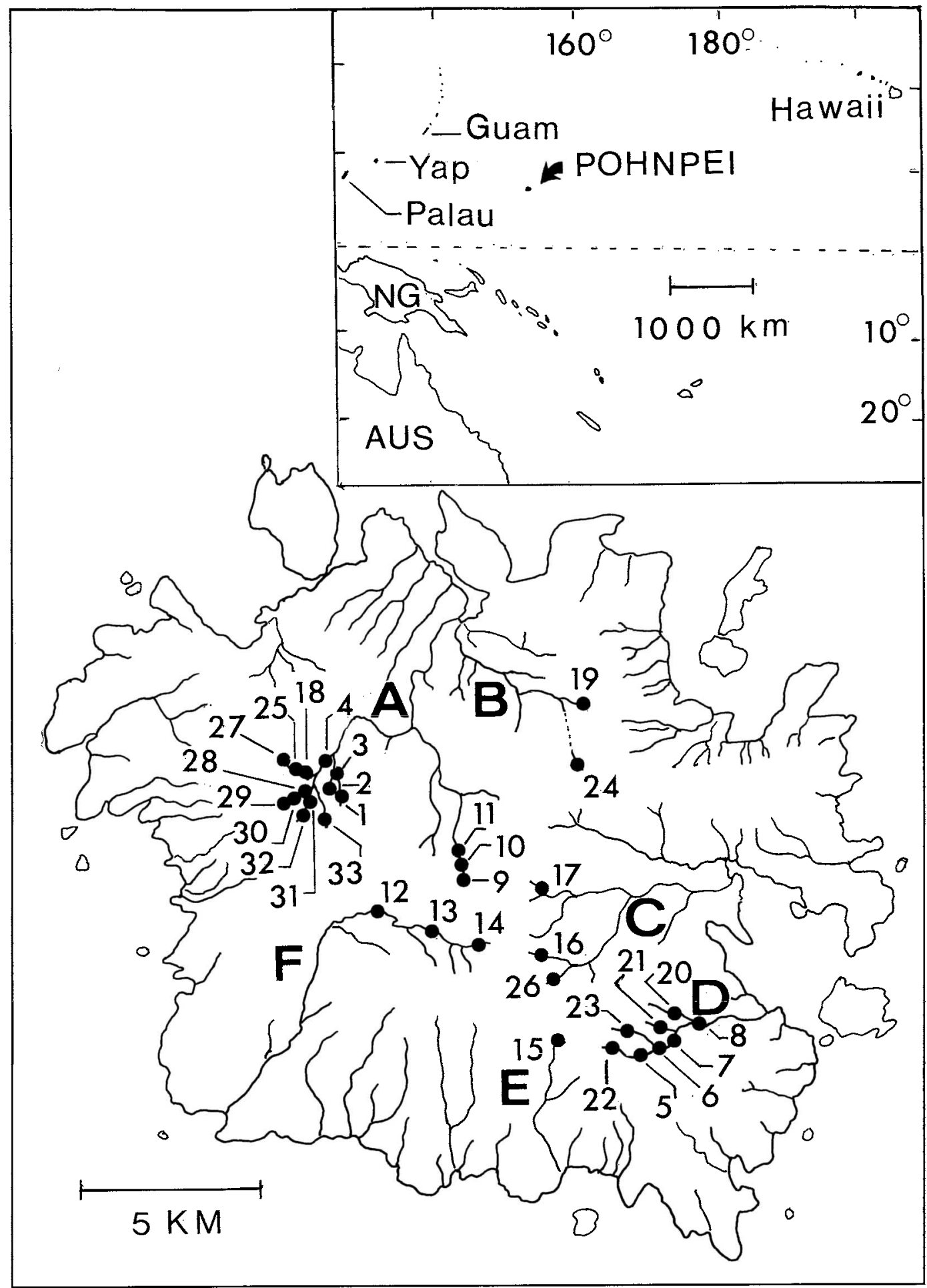

Figure 1. Location map for Pohnpei and collecting stations for 1999 headwaters survey. A, Nanpil-Kiepw River; B, Meitik River; C, Senipehn River; D, Mahnd River; E, Neh River; F, Lehn Mesi River; AUS, Australia; NG, New Guinea; broken line, equator. 
trum to the tip of the telson (with abdomen extended on a flat surface). Standard postorbital carapace length was measured on all ovigerous females among atyids. Measurements of total length in $M$. lar and $M$. latimanus were submitted to Student's $t$-test to test for sexual dimorphism and interspecific differences in body size.

\section{SPECIES ACCOUNTS}

\section{Palaemonidae}

Macrobracbium lar and $M$. latimanus. Both species of Macrobracbium are widespread in the Indo-West Pacific region from East Africa (in the case of $M$. lar) and India and Sri Lanka (for $M$. latimanus) to as far east as the Marquesas Islands, Polynesia (Chace and Bruce 1993), and $M$. lar has been introduced to Hawaici (Kubota 1972). Both are common on Pohnpei (Maciolek and Ford 1987, Nelson et al. 1996; this study), but $M$. latimanus is more abundant and widespread in headwater streams than is $M$. lar, accounting for 253 $(82 \%)$ of the 310 specimens, and reaching farther into the smaller tributaries at higher elevations. In the five stations above $350 \mathrm{~m}$ $(14,15,22,24,27)$, we collected only one $M$. lar in contrast to $65 \mathrm{M}$. latimanus. We collected $M$. latimanus in all six rivers and in 27 $(82 \%)$ of 33 sampling stations. Macrobracbium latimanus may have been present also in four additional stations $(7,9,11,17)$ where examples of Macrobracbium unidentified as to species were observed but not collected. Station 1 , located on a shallow, narrow tributary of the Nanpil-Kiepw River, is the only site where we did not observe Macrobrachium. We collected $M$. lar at $14(42 \%)$ of the stations, but none in the Meitik, Senipehn, and Neh Rivers (all 48 specimens were $M$. latimanus), although it may occur in one or more of those drainages, especially at lower elevations.

Macrobracbium lar averaged larger than $M$. latimanus both in males $(t=2.75$, df $=104$, $P<0.01)$ and in ovigerous females $(t=9.70$, $\mathrm{df}=52, P<0.01$ ) (Table 1). Males of $M$. latimanus were significantly larger than females $(t=5.90, \mathrm{df}=236, P<0.01)$, but sexual dimorphism in total length was less

\section{TABLE 1}

Total Length Measurements (Range, $n$, Mean \pm SD) for Macrobracbium spp. Collected in Headwater Streams on Pohnpei during February-November 1999

\begin{tabular}{lcc}
\hline \hline Size Class and Sex & M. lar & M. latimanus \\
\hline$>30.0 \mathrm{~mm}$ & & \\
Males & $35.0-141.5(30)$ & $30.9-105.0(162)$ \\
& $82.9 \pm 33.2$ & $65.5 \pm 15.0$ \\
All females & $49.9-108.7(25)$ & $31.2-92.1(76)$ \\
& $81.7 \pm 16.8$ & $54.4 \pm 12.6$ \\
Ovigerous females & $73.2-106.2(11)$ & $34.3-92.1(43)$ \\
& $89.3 \pm 9.0$ & $56.4 \pm 12.0$ \\
<30.0 mm & $29.9(1)$ & $21.3-29.9(11)$ \\
Males & $(0)$ & $25.3 \pm 3.1$ \\
Females & & $(0)$ \\
\hline
\end{tabular}

evident in $M$. lar $(t=0.17, \quad \mathrm{df}=53$, $P>0.05)$, although 10 of the 30 males $(33 \%)$ were larger than the largest among 25 females. Immature specimens less than 30.0 $\mathrm{mm}$ in total length were scarce in all our samples; all 12 were males, and all but one were $M$. latimanus.

The sample of ovigerous females was too small to assess seasonality in reproduction confidently. Nevertheless, the scanty evidence indicates that $M$. latimanus breeds throughout the year, because $14(74 \%)$ of 19 females collected during February-May were ovigerous, as were $29(50 \%)$ of 58 collected during August-November. In the case of $M$. lar, $11(55 \%)$ of 20 females collected during February-May were ovigerous, but none among the six collected during AugustNovember, although this was possibly an artifact of small sample size.

\section{Atyidae}

Atyoida pilipes. This species is widespread in the Indo-West Pacific region and ranges from the Sunda Islands, Indonesia, to as far east as the Gambier Islands, Polynesia (Chace 1997). It was abundant in Pohnpei headwaters, accounting for $489(72.3 \%)$ of 676 atyids collected in 1999 (Table 2). We collected it at $24(72.7 \%)$ of the 33 stations and in five of six rivers; its absence from the Neh 


\section{TABLE 2}

Distribution of Atyid Shrimps Collected in Pohnpei Headwater Streams during February-November 1999, with Percentages across Species in Parentheses

\begin{tabular}{lccc}
\hline \hline River System & $\begin{array}{c}\text { Atyoida } \\
\text { pilipes }\end{array}$ & $\begin{array}{c}\text { Caridina } \\
\text { typus }\end{array}$ & $\begin{array}{c}\text { Caridina } \\
\text { weberi }\end{array}$ \\
\hline Nanpil Kiepw & $195(83.3)$ & $8(3.4)$ & $31(13.3)$ \\
Meitik & $100(100)$ & 0 & 0 \\
Senipehn & $105(87.5)$ & 0 & $15(12.5)$ \\
Mahnd & $39(38.2)$ & $2(2.0)$ & $61(59.8)$ \\
Neh & 0 & $33(97.0)$ & $1(3.0)$ \\
Lehn Mesi & $50(58.1)$ & 0 & $36(41.9)$ \\
\hline
\end{tabular}

\section{TABLE 3}

Relative Abundance ${ }^{a}$ of Ovigerous Females of Atyid Shrimps Collected in Pohnpei Headwater Streams during February-November $1999^{b}$

\begin{tabular}{lccc}
\hline \hline Month & Atyoida pilipes & $\begin{array}{c}\text { Caridina } \\
\text { typus }\end{array}$ & $\begin{array}{c}\text { Caridina } \\
\text { weberi }\end{array}$ \\
\hline February & $1 / 17(5.9)$ & $0 / 1$ & $7 / 49(8.9)$ \\
March & $1 / 38(2.6)$ & $2 / 9(22.2)$ & $6 / 30(20.0)$ \\
April & $61 / 79(77.2)$ & $0 / 24$ & $4 / 15(26.7)$ \\
May & $50 / 134(37.3)$ & $0 / 2$ & $8 / 32(25.0)$ \\
August & $13 / 80(16.3)$ & & $1 / 9(11.1)$ \\
September & $17 / 51(33.3)$ & & $5 / 9(55.6)$ \\
October & $10 / 45(22.2)$ & $0 / 7$ & \\
November & $14 / 45(31.1)$ & & \\
\hline
\end{tabular}

a The number of ovigerous females divided by the total number of specimens collected (by species), with percentages in parentheses.

${ }^{b}$ Exchuding June and July when no collections were made.

River (with only one station) may be artifactual. It is especially abundant in cascades and waterfalls, clinging to rocks behind the main flow of the current. At some localities, it was possible to collect $5-10$ at a time simply by passing a cupped hand along the under and lateral surfaces of the rocks. Ovigerous females were collected throughout the year, with proportionally more in April (Table 3); however, this finding is based almost entirely on one sample from station 16 on the Senipehn River, where 61 of $73(83.6 \%)$ were ovigerous. In Palau, Bright (1979) found ovigerous females relatively most numerous in August. Bascom (1946) alluded to an annual upstream migration of atyids in Pohnpei
TABLE 4

Carapace Length in Ovigerous Females of Atyid Shrimps Collected in Pohnpei Headwater Streams during February-November 1999

\begin{tabular}{lrc}
\hline Species & $n$ & Carapace Length (mm) \\
\hline Atyoida pilipes & 167 & $5.6-8.3$ \\
Caridina typus & 2 & $3.9-4.3^{a}$ \\
Caridina weberi & 31 & $4.3-5.5$ \\
Caridina sp. & 1 & 3.5 \\
\hline
\end{tabular}

a Another collected in the Nanpil River (upper extension of station 29) at $336-366 \mathrm{~m}$ on 30 March 2000 measured $5.9 \mathrm{~mm}$.

rivers around April that probably included this species.

Caridina typus. This species has a broad distribution in the Indo-West Pacific region from eastern Africa to Polynesia (Chace 1997). It was the least common of the three atyids in Pohnpei headwater streams, accounting for only $43(6.4 \%)$ of the specimens collected, with 33 of them (97\%) being from station 15 on the Neh River (Table 2). It was unrecorded in the lower reaches by Nelson et al. (1996) and collected there only in small numbers by Maciolek and Ford (1987). Small to medium-sized adults from Pohnpei lack teeth on the ventral margin of the rostrum, whereas in other parts of its range the adults usually are armed with one to six teeth (Chace 1997). The two ovigerous females (both from station 15) were among the smallest of any ovigerous specimens we collected in 1999 (Table 3), but another collected in the Nanpil River in March 2000 exceeds the upper range limit for carapace length in our samples of $C$. weberi (Table 4).

Caridina weberi. This shrimp is another wide-ranging Indo-West Pacific species. It has been recorded from India to as far east as the Marquesas Islands, Polynesia (Hung et al. 1993, Chace 1997). It was fairly common in Pohnpei headwaters, accounting for $144(21.3 \%)$ of the atyids collected, and at $14(42.4 \%)$ of the 33 stations. It was common also in the surveys at lower elevations (Maciolek and Ford 1987, Nelson et al. 1996). We found ovigerous females during each month specimens of $C$. weberi were col- 
lected (February-May, August, and September), but this species was not among the 97 atyids collected during October and November 1999 .

The position of the antennal spine relative to the inferior orbit is highly variable in Pohnpei specimens. Throughout much of its geographic range, $C$. weberi usually has the antennal spine fused with the inferior orbit (Choy 1991, Chace 1997), but in most of the Pohnpei specimens the spine is located below and distinct from the orbit. In addition, some of the Pohnpei specimens exceed the upper range limit of 20 dorsal rostral teeth reported by Chace (1997) for the species.

\section{DISCUSSION}

Of the 10 species of decapods recorded in Pohnpei rivers (see Maciolek and Ford 1987), five were among the 986 specimens collected in headwater streams in 1999. Previously recorded species not encountered include a grapsid crab (Parasesarma sp.) and the atyids Atyopsis spinipes, Caridina brachydactyla, $C$. longirostris, and $C$. vitiensis. One Caridina with an apparently deformed rostrum we collected in the Nanpil River in March 2000 was unidentified as to species. The highest elevation that specimens were found in this study was $604 \mathrm{~m}$ on the Senipehn River, above station 26, where we collected seven Atyoida pilipes on 19 April 2000. None of the 10 species is endemic to Pohnpei, and all five from the uplands are widely distributed among tropical western Pacific islands. Such broad distributions are in marked contrast to the high level of endemism among gobiid fishes from the same localities; at least three of the five gobies $(60 \%)$ are endemic to the island (Buden et al. in press). The shrimps and gobies we collected all share a diadromous lifestyle, including marine dispersal as larvae and in some cases juveniles (Maciolek and Ford 1987, Parenti and Maciolek 1993, Nelson et al. 1996, 1997). We are uncertain as to the selection pressures contributing to the disparity in levels of endemism in these two prominent components of the stream macrofauna.

Caridina typus was scarce in our samples
( $6.4 \%$ of the atyids collected in 1999), but the other four decapod species were encountered regularly and at no fewer than 14 of 33 stations. Caridina typus was poorly represented also at lower elevations on Pohnpei (Maciolek and Ford 1987, Nelson et al. 1996), and it was uncommon in the upper reaches of rivers on Palau (Bright 1979). However, it was common "in first order streamlets [on Palau] which originated within $1-2 \mathrm{~km}$ of the sea" (Bright 1989:34), and its abundance on Yap (67\% of the specimens collected in September 1988) may be due to a preponderance of such habitat (Bright 1989).

Atyoida pilipes was found mainly in cascades and waterfalls unlike the other atyids, which were found mainly in pools, runs, and riffles. Its habitat preference, together with chelae adapted for both filter feeding and sweeping (Chace 1983) as opposed to substrate feeding, and its large body size among atyids suggest that $A$. pilipes occupies a niche markedly distinct from that of any of the four other decapod species. Caridina typus and $C$. weberi overlap broadly in body size, have morphologically similar feeding appendages, and probably very similar feeding ecologies. Competitive exclusion may be a factor contributing to the pattern of distribution of these two species on Pohnpei, where (small sample sizes notwithstanding) $95 \%$ of the $C$. typus were collected in localities that accounted for only $22 \%$ of the $C$. weberi. In addition, $C$. weberi was not encountered in two of the five stations where C. typus was collected. In another possible case of exclusion involving C. typus, Bright (1989) reported that nearly $80 \%$ of $C$. gracilirostris collected on Yap were in areas where C. typus was absent.

How the two much larger palaemonids partition resources is uncertain. Macrobrachium lar is "an omnivore with carnivorous tendencies" (Maciolek 1972:554), and $M$. latimanus almost certainly feeds similarly. But the two species differ in body size and in the length and robustness of their chelae, and $M$. latimanus greatly outnumbers $M$. lar in the higher elevations. Macrobracbium latimanus also is common in the upper reaches of streams in French Polynesia (Marquet 1991, 
Fossati and Danigo 1995), but apparently is limited to the lower reaches of streams in Palau (Bright 1979).

Large body size, palatability, and widespread distribution are among the characteristics that make Macrobracbium lar a potential candidate for aquaculture throughout the tropical Pacific (Maciolek 1972). Traditional small-scale fisheries for both $M$. lar and $M$. latimanus have long existed among Pacific islands (Holthuis 1980). Pohnpeians harvest Macrobracbium spp. from time to time, and atyids occasionally also are eaten (P. Gallen, pers. comm.). However, freshwater shrimps are not an important part of Pohnpeian diet. One of the reasons is that river shrimps are considered to be somewhat plebeian by many islanders, more suited as survival fare and for children to catch and eat opportunistically (P. Gallen, pers. comm.). Some residents indicated that upland populations are inconveniently located and those in the lower reaches may be contaminated by pollution. A. Edward (pers. comm.) received unconfirmed reports that some islanders developed a skin rash after eating freshwater shrimp.

Although largely ignored now, river shrimps were utilized more in the past when imported foods (upon which the people now largely depend) and advanced technology for harvesting marine resources were not available. Bascom (1946:251) stated that "freshwater shrimp [likathapw or likosiang = Macrobrachium spp.?] ... is caught with dip nets in the mountain streams by women.... A similar shrimp (likashapw en seth) and a tiny shrimp (lur) described as the size of a grain of rice are caught in the salt water. The latter swims into the lagoon and up the rivers by the millions each year about April, when men, women and children stand in the shallow water along the river banks and scoop them up with baskets, bowls, or whatever is handy." Many islanders we queried were familiar with the name "luhr," applying it to Atyoida pilipes (and possibly also Caridina spp.), but we were unable to confirm annual upstream migrations, nor were we able to assign the name "likathapw en seth" (literally "shrimp of the ocean") to any one species.

Although freshwater crustaceans are not favored as food by Pohnpeians, they doubtless contribute to the economy of the streams, recycling nutrients and providing food for the other inhabitants. Decapods are often the dominant invertebrates in tropical island streams (Bright 1982). Nelson et al. (1996) recorded an average of 1.8 Macrobracbium spp. per square meter in the Lehn Mesi and Nanpil-Kiepw Rivers, and Bright (1979) recorded juvenile Atyoida pilipes in densities of at least $350 / \mathrm{m}^{2}$ in downstream sites on Palau and went on to state that decapods contributed up to $85 \%$ of the benthic biomass in pools and cascades. Our qualitative observations indicate that decapods are the most numerous and ubiquitous of the stream macrofauna on Pohnpei.

The decapod crustaceans in Pohnpei rivers currently appear unthreatened and unendangered. The chief predator of shrimp in the upper reaches of the rivers probably is an eel, Anguilla marmorata, which reaches lengths of about $2 \mathrm{~m}$ and is common throughout. The resident islanders harvest shrimp only occasionally and pose no direct threat. However, progressive encroachment of agriculture into the highlands, including the clearing of 1 - to 2-ha plots on montane slopes adjacent to headwater streams, is likely to alter stream ecology (light, temperature, turbidity, volume fluctuations, etc.) in ways that may impact negatively on many stream species.

\section{ACKNOWLEDGMENTS}

We thank D. Kesler and K. Rhodes for their assistance on several collecting trips, and we are grateful for the information on Pohnpeian customs and traditions provided by A. Edward, Sea Grant Agent for the Federated States of Micronesia, and P. Gallen, Education Department, College of Micronesia, FSM.

\section{Literature Cited}

Bascom, W. R. 1946. Ponape: A Pacific economy in transition. Pacific Science Office, National Research Council, Washington, D.C., and U.S. Commercial Com- 
pany, Economic Survey of Micronesia, Honolulu.

Bright, G. 1979. The inland waters of Palau, Caroline Islands. Report: Office of the Trust Territory of the Pacific Islands. Koror, Palau.

Bright, G. R. 1982. Secondary benthic production in a tropical island stream. Limnol. Oceanogr. 27:472-480.

- 1989. The freshwater decapod crustaceans of Yap, Caroline Islands. Pages 33-36 in S. G. Nelson, ed. The inland aquatic habitats of Yap. Univ. Guam Mar. Lab. Tech. Rep. 92.

Buden, D. W., D. B. Lynch, and R. E. Watson. (in press). The gobiid fishes (Teleostei: Gobioidei: Sicydiinae) of the headwater streams of Pohnpei, Eastern Caroline Islands, Federated States of Micronesia. Micronesica.

Chace, F. A., Jr. 1983. The Atya-like shrimps of the Indo-Pacific region (Decapoda: Atyidae). Smithson. Contrib. Zool. 384:154.

1997. The caridean shrimps (Crustacea: Decapoda) of the Albatross Philippine Expedition 1907-1910, part 7: Families Atyidae, Eugonatonotidae, Rhynchocinetidae, Bathypalaemonellidae, Processidae and Hippolytidae. Smithson. Contrib. Zool. 587:1-106.

Chace, F. A., Jr., and A. J. Bruce. 1993. The caridean shrimps (Crustacea: Decapoda) of the Albatross Philippine Expedition 19071910, part 6: Superfamily Palaemonoidea. Smithson. Contrib. Zool. 543:1-152.

Choy, S. C. 1991. The atyid shrimps of Fiji with description of a new species. Zool. Meded. (Leiden) 65:343-362.

Fossati, O., and H. Danigo. 1995. A new sampling method for freshwater shrimps. Mesogee 54:43-48.

Holthuis, L. B. 1980. Shrimps and prawns of the world: An annotated catalogue of species of interest to fisheries. FAO [Food and Agriculture Organization of the United Nations, Rome] Species Catalogue, Vol 1. FAO Fish. Synop. 125:1-271.

Hung, M.-S., T.-Y. Chan, and H.-P. Yu. 1993. Atyid shrimps (Decapoda: Caridea) of Taiwan, with descriptions of three new species. J. Crustacean Biol. 13:481-503.

Laird, W. E. 1982. Soil survey of island of Pohnpei, Federated States of Micronesia. U.S. Department of Agriculture, Soil Conservation Service. 81 p.

Kubota, W. T. 1972. The biology of an introduced prawn, Macrobrachium lar (Fabricius), in Kahana Stream. M.S. thesis, University of Hawai'i at Mānoa, Honolulu.

Maciolek, J. A. 1972. Macrobracbium lar as a culture prawn in the tropical insular Pacific. Pages 550-558 in Western Association of State Game and Fish Commissioners. Proceedings of the 52nd Annual Conference of Western Association of State Game and Fish Commissioners, Portland, Oregon.

Maciolek, J. A., and J. I. Ford. 1987. Macrofauna and environment of the NanpilKiepw River, Ponape, eastern Caroline Islands. Bull. Mar. Sci. 41:623-632.

MacLean, C. D., T. G. Cole, C. D. Whitesell, M. V. Falanruw, and A. H. Ambacher. 1986. Vegetation survey of Pohnpei, Federated States of Micronesia. U.S. For. Serv. Res. Bull. PSW-18.

Marquet, G. 1991. Freshwater crustaceans of French Polynesia: Taxonomy, distribution and biomass (Decapoda). Crustaceana (Leiden) 61:125-140.

Merlin, M., D. Jano, W. Raynor, T. Keene, J. Juvic, and B. Sebastian. 1992. Tuhke en Pohnpei [Plants of Pohnpei]. Environmental and Policy Institute of the EastWest Center, Honolulu. 94 p.

Nelson, S. G., F. A. Camacho, J. E. Parham, R. B. Tibbatts, T. Leberer, and B. D. Smith. 1996. Surveys of the macrofauna of the Nanpil Kiepw and Lehn Mesi Rivers of Pohnpei. Univ. Guam Mar. Lab. Tech. Rep. 103.

Nelson, S. G., J. E. Parham, R. B. Tibbatts, F. A. Camacho, T. Leberer, and B. D. Smith. 1997. Distributions and microhabitats of the amphidromous gobies in streams of Micronesia. Micronesica 30:8391.

Office of Planning and Statistics. 1996. Na- 
tional detailed tables, 1994 FSM Census of Population and Housing. National Government, Federated States of Micronesia, Palikir, Pohnpei.

Parenti, L. R., and J. A. Maciolek. 1993. New sicydiine gobies from Ponape and Palau, Micronesia, with comments on systematics of the subfamily Sicydiinae (Teleostei: Gobiidae). Bull. Mar. Sci. 53:945-972.

Trustrum, N. A. 1996. Pohnpei's watershed spatial plan and management guidelines [Consultant's report prepared for the Asian Development Bank, T. A. No. FSM-1925; Watershed Management and Environment]. Landcare Research, New Zealand, Ltd., Palmerston North, New Zealand.

U.S. Army Corps of Engineers. 1986. Pohnpei coastal resource inventory. U.S. Army Engineer Pacific Ocean Division, Fort Shafter, Hawai'i. 170 p. 